\title{
Interpreting Neonatal Growth Parameters in Oman

\author{
Are we doing it right?
}

Reem M. Abdulrahim, ${ }^{1}$ "Ahmed B. Idris, ${ }^{2}$ Asad Ur-Rahman, ${ }^{2}$ Mohamed Abdellatif, ${ }^{2}$ Nigel Fuller ${ }^{1}$

$$
\text { تفسير مؤشرات نمو المواليد في عمان }
$$

ريم عبد الرحيم، أحمد بابكر إدريس، أسد الرحمن، محمد عبد اللطيف، نايجل فلر

ABSTRACT: Objectives: This study aimed to compare reference anthropometric measures of Omani neonates with the international standard growth charts of the World Health Organization (WHO) in order to determine the appropriateness of these growth charts to assess the growth of Omani neonates. Methods: This cross-sectional study included all healthy full-term Omani neonates born between November 2014 and November 2015 at the Sultan Qaboos University Hospital, Muscat, Oman. Birth weight, length and head circumference measurements were identified and compared to those of the 2006 WHO growth charts. Results: A total of 2,766 full-term neonates were included in the study, of which 1,401 (50.7\%) were male and 1,365 (49.3\%) were female. Mean birth weights for Omani males and females were $3.16 \pm 0.39 \mathrm{~kg}$ and $3.06 \pm 0.38 \mathrm{~kg}$, respectively; these were significantly lower than the WHO standard measurements $(P<0.001)$. Similarly, the mean head circumferences of Omani males and females $(33.8 \pm 1.27 \mathrm{~cm}$ and $33.3 \pm 1.26 \mathrm{~cm}$, respectively) were significantly lower than those reported in the WHO growth charts $(P<0.001)$. In contrast, mean lengths for Omani males and females $(52.0 \pm 2.62 \mathrm{~cm}$ and $51.4 \pm 2.64$ $\mathrm{cm}$, respectively) were significantly higher than the WHO standard measurements $(P<0.001)$. Conclusion: The WHO growth charts might not be appropriate for use with Omani neonates; possible alternatives should therefore be considered, such as national growth charts based on local data.

Keywords: Anthropometry; Growth Charts; Neonates; World Health Organization; Oman.

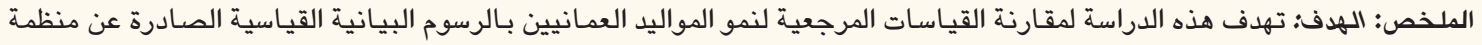

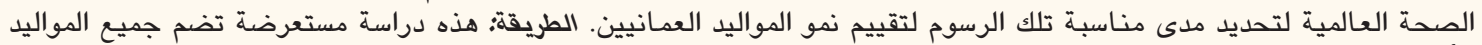

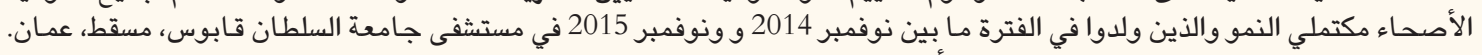

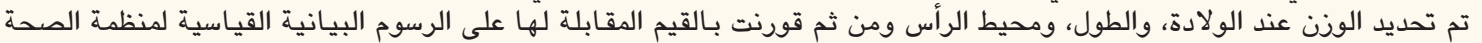

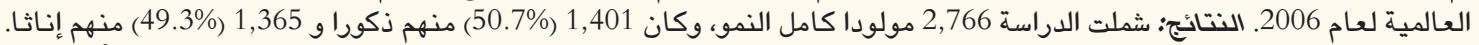

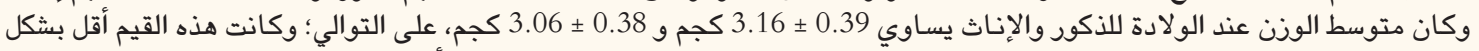

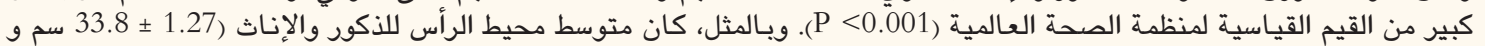

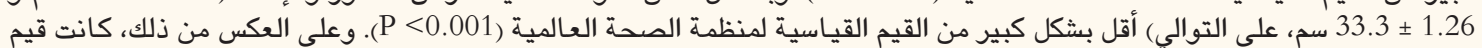

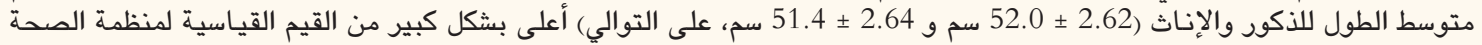

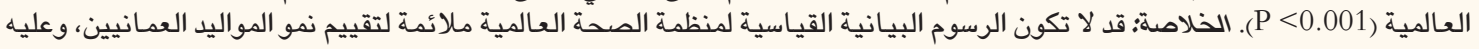

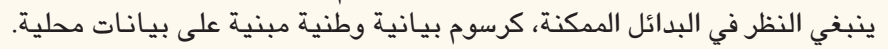

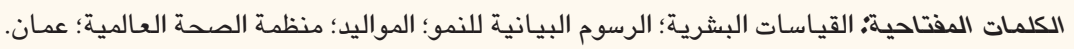

\section{AdVANCES IN KNOWLEDGE}

The results of this study revealed that full-term Omani neonates have significantly lower birth weights and head circumferences and greater lengths than the international standards reported in the World Health Organization (WHO) 2006 growth charts.

\section{Application to Patient Care}

This study provides preliminary evidence that the WHO standard growth charts might not be the best tool to assess the growth of fullterm Omani neonates, indicating potential gaps in the interpretation of anthropometric measurements.

Based on these findings, clinicians are advised to balance the use of international growth charts with a degree of well-informed clinical judgment in order to help reduce unnecessary clinic visits, investigations, costs and parental anxiety.

A NTHROPOMETRY IS THE QUANTITATIVE ASSESSment of an individual's physical dimensions which, in combination with age and gender, can subsequently be used to assess growth status. ${ }^{1}$
Neonatal anthropometric measurements-such as birth weight, height and head circumference-are considered rapid, reliable and feasible indicators of fetal intrauterine and postnatal growth, as well as 
predictors of potential short- and long-term health complications. ${ }^{2}$ In turn, any significant deviation from normal anthropometric values may be associated with increased perinatal morbidity and mortality. ${ }^{3}$

In combination with gestational age, birth weight helps to group newborns into small for gestational age (SGA), appropriate for gestational age and large for gestational age (LGA) categories, according to a normal distribution curve for weight in which the $10^{\text {th }}$ and $90^{\text {th }}$ percentiles mark infants as either SGA or LGA, respectively. ${ }^{4}$ Neonates who are SGA are subject to extensive clinical interventions and investigations and are likely to have congenital abnormalities, while LGA newborns are prone to a wide range of neonatal complications such as respiratory distress, hypoglycaemia and polycythaemia., ${ }^{3,5}$ Additionally, head circumference values below the third percentile (i.e. microcephaly) might indicate serious genetic or acquired health problems. ${ }^{6}$

Two types of growth charts are regularly used to assess neonatal anthropometric measurements. While reference charts merely describe the growth patterns of a certain population, standard charts apply strict inclusion and exclusion criteria to determine the optimal growth of children in favourable socioeconomic and health conditions. ${ }^{7}$ Internationally, the most widely used growth charts are the standard charts developed by the World Health Organization (WHO) which describe growth in optimal conditions. ${ }^{8}$ These charts were developed as a result of the Multicentre Growth Reference Study (MGRS) in which six countries participated, including Oman. ${ }^{9}$

Currently, Oman has no specific national growth charts and the 2006 WHO standard charts have been adopted to assess the growth of Omani neonates. ${ }^{10}$ However, marked variation in the interpretation of child growth measurements can occur depending on the growth chart used. ${ }^{11}$ The potential misclassification of healthy children as having growth abnormalities has critical public health implications, particularly in terms of the burden on future healthcare management. Therefore, this study aimed to identify reference anthropometric measurements among Omani neonates and compare these to the WHO international standards in order to determine the appropriateness of the WHO growth charts within the Omani population.

\section{Methods}

This retrospective cross-sectional study included all healthy full-term Omani neonates born at the Sultan Qaboos University Hospital (SQUH) in Muscat, Oman, between November 2014 and November 2015. Only those neonates of Omani nationality between 37-42 gestational weeks and born from singleton pregnancies were included. Cases with significant maternal or neonatal illness were excluded. Neonatal characteristics and anthropometric measurements, including gender, birth weight, length and head circumference, were obtained from the electronic hospital information system. Gestational age was calculated according to dates of the mother's last menstrual period and delivery. Birth weight was measured using digital scales to a precision level of $0.001 \mathrm{~kg}$. A regular measuring tape was used to measure length to a $0.1 \mathrm{~cm}$ precision level. Head circumference to the nearest $0.1 \mathrm{~cm}$ was calculated using flexible non-stretchable tape.

In terms of sample size, the WHO Expert Committee recommends including at least 200 individuals in each age and gender group in order to construct reference growth curves with sufficiently precise estimates. ${ }^{12}$ However, no standard approach exists to establish precision for each percentile. Therefore, the Omani reference data were taken from a single time point with precise estimates of weight, length and head circumference. A minimum of 200 male and 200 female neonates were considered sufficient to establish precision at the $10^{\text {th }}$ and $90^{\text {th }}$ percentiles within 0.1 of a standard deviation (SD), with the range between the $3^{\text {rd }}$ and $97^{\text {th }}$ percentiles considered to be four SDs. ${ }^{13}$ The mean values and SDs for birth weight, length and head circumference measurements were calculated for males and females separately. Moreover, anthropometric measurements for the $3^{\text {rd }}, 10^{\text {th }}, 25^{\text {th }}, 50^{\text {th }}, 75^{\text {th }}, 90^{\text {th }}$ and $97^{\text {th }}$ percentiles were also calculated. Subsequently, the mean values and percentiles of the Omani sample were compared to the standard measurements and percentiles reported in the 2006 WHO standard growth charts. ${ }^{14}$

Data were analysed using the Statistical Package for the Social Sciences (SPSS) software, Version 21.0 (IBM Corp., Armonk, New York, USA). Mean values were compared using a Student's t-test calculator (GraphPad Software Inc., La Jolla, California, USA). Percentiles were compared graphically by plotting the data points in a Word document, Version 2016 (Microsoft Inc., Redmond, Washington, USA). A $P$ value of $<0.050$ was considered statistically significant.

Ethical approval for this study was obtained from the Medical Ethics Committee of the College of Medicine \& Health Sciences, Sultan Qaboos University (MREC \#1163). 


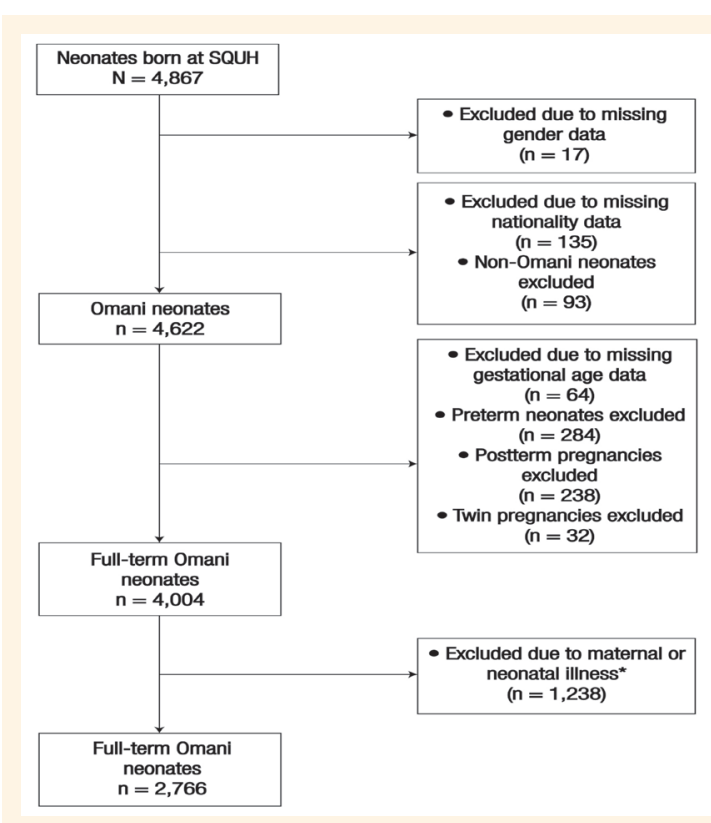

Figure 1: Diagram showing the application of inclusion and exclusion criteria to determine the final sample used in the current study.

SQUH = Sultan Qaboos University Hospital.

"Including a variety of illnesses such as diabetes, hypertension, anaemia, asthma, bleeding disorders, infectious diseases and thyroid, renal, autoimmune, neurological and psychiatric problems.

\section{Results}

A total of 4,867 neonates were born at SQUH during the study period. Following application of the inclusion/exclusion criteria, there were 2,766 eligible mother-neonate pairs [Figure 1]. While missing values were reported in the birth weight $(0.4 \%)$, length $(0.5 \%)$ and head circumference $(0.5 \%)$ categories, the total percentage of missing data was considered acceptable at $<5 \% .{ }^{15}$ Of the 2,766 neonates, 1,401 (50.7\%) were
Table 1: Percentile values for birth weight, length and head circumference measurements among Omani neonates born at the Sultan Qaboos University Hospital, Muscat, Oman $(\mathrm{N}=2,766)$

\begin{tabular}{|c|c|c|c|c|c|c|c|}
\hline \multirow[t]{2}{*}{ Measurement } & \multicolumn{7}{|c|}{ Percentile } \\
\hline & $3^{\text {rd }}$ & $10^{\text {th }}$ & $25^{\text {th }}$ & $50^{\text {th }}$ & $75^{\text {th }}$ & $90^{\text {th }}$ & $97^{\text {th }}$ \\
\hline \multicolumn{8}{|c|}{ Birth weight in $\mathrm{kg}$} \\
\hline Males & 2.47 & 2.69 & 2.89 & 3.14 & 3.41 & 3.68 & 3.95 \\
\hline Females & 2.36 & 2.56 & 2.79 & 3.07 & 3.31 & 3.55 & 3.77 \\
\hline \multicolumn{8}{|l|}{ Length in $\mathrm{cm}$} \\
\hline Males & 48.0 & 49.0 & 51.0 & 52.0 & 54.0 & 55.0 & 56.0 \\
\hline Females & 47.0 & 49.0 & 50.0 & 52.0 & 53.0 & 54.0 & 56.0 \\
\hline \multicolumn{8}{|c|}{ Head circumference in $\mathrm{cm}$} \\
\hline Males & 31.5 & 32.0 & 33.0 & 34.0 & 34.5 & 35.5 & 36.0 \\
\hline Females & 31.0 & 32.0 & 32.5 & 33.0 & 34.0 & 35.0 & 36.0 \\
\hline
\end{tabular}

male and 1,365 (49.3\%) were female. Table 1 shows the percentile values for birth weight, length and head circumference according to gender.

For the male neonates, mean birth weight, length and head circumference values were $3.16 \pm 0.39 \mathrm{~kg}$, $52.0 \pm 2.62 \mathrm{~cm}$ and $33.8 \pm 1.27 \mathrm{~cm}$, respectively. The same measurements for females were $3.06 \pm 0.38 \mathrm{~kg}$, $51.4 \pm 2.64 \mathrm{~cm}$ and $33.3 \pm 1.26 \mathrm{~cm}$, respectively. Both Omani male and female neonates had significantly lower mean birth weights and head circumferences when compared to data from the standard WHO charts $(3.30 \pm 0.40 \mathrm{~kg}$ and $3.20 \pm 0.40 \mathrm{~kg}$, respectively, and $34.5 \pm 1.20 \mathrm{~cm}$ and $33.9 \pm 1.10 \mathrm{~cm}$, respectively; $P<0.001$ each). In contrast, the mean length of Omani male and female neonates was significantly higher than that indicated in the WHO charts $(49.9 \pm 1.89 \mathrm{~cm}$

Table 2: Comparison of mean birth weight, length and head circumference measurements among Omani neonates born at the Sultan Qaboos University Hospital, Muscat, Oman $(\mathrm{N}=2,766)$ with the 2006 World Health Organization standard growth charts ${ }^{14}$

\begin{tabular}{|c|c|c|c|c|c|c|c|c|}
\hline \multirow[t]{2}{*}{ Measurement } & \multicolumn{3}{|c|}{ Omani sample } & \multicolumn{3}{|c|}{ WHO standards } & \multirow[t]{2}{*}{$95 \% \mathrm{CI}$} & \multirow[t]{2}{*}{$P$ value } \\
\hline & $\mathbf{n}$ & Mean \pm SD & SE & $\mathbf{n}$ & Mean \pm SD & SE & & \\
\hline \multicolumn{9}{|c|}{ Birth weight in $\mathrm{kg}$} \\
\hline Males & 1,401 & $3.16 \pm 0.39$ & 0.01 & 890 & $3.30 \pm 0.40$ & 0.01 & $0.107-0.173$ & $<0.001$ \\
\hline Females & 1,365 & $3.06 \pm 0.38$ & 0.01 & 838 & $3.20 \pm 0.40$ & 0.01 & $0.107-0.173$ & $<0.001$ \\
\hline \multicolumn{9}{|l|}{ Length in $\mathrm{cm}$} \\
\hline Males & 1,401 & $52.0 \pm 2.62$ & 0.07 & 893 & $49.9 \pm 1.89$ & 0.06 & $1.901-2.298$ & $<0.001$ \\
\hline Females & 1,365 & $51.4 \pm 2.64$ & 0.07 & 842 & $49.1 \pm 1.89$ & 0.06 & $2.094-2.505$ & $<0.001$ \\
\hline \multicolumn{9}{|c|}{ Head circumference in $\mathrm{cm}$} \\
\hline Males & 1,401 & $33.8 \pm 1.27$ & 0.03 & 890 & $34.5 \pm 1.20$ & 0.04 & $0.595-0.804$ & $<0.001$ \\
\hline Females & 1,365 & $33.3 \pm 1.26$ & 0.03 & 838 & $33.9 \pm 1.10$ & 0.04 & $0.496-0.703$ & $<0.001$ \\
\hline
\end{tabular}

$S D=$ standard deviation; $S E=$ standard error $; W H O=$ World Health Organization; $C I=$ confidence interval . 
A

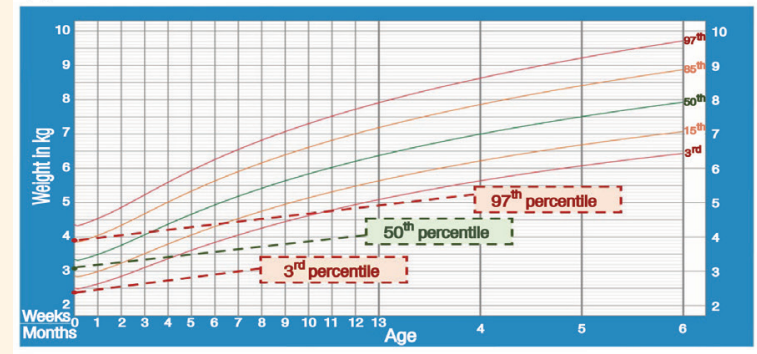

B

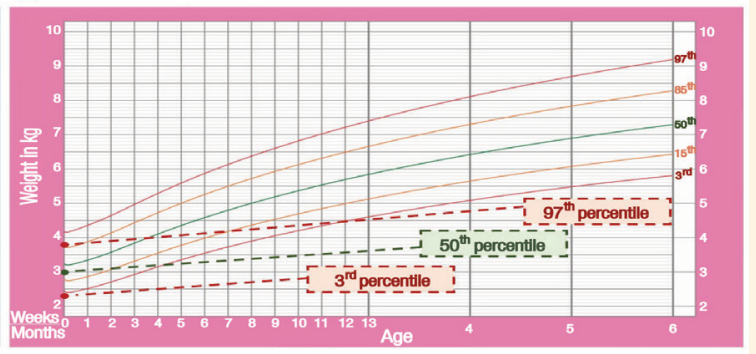

Figure 2: Comparison of birth weight percentiles for (A) males and (B) females among Omani neonates (dotted lines) born at the Sultan Qaboos University Hospital, Muscat, Oman $(\mathrm{N}=2,766)$ with the 2006 World Health Organization standard growth charts (continuous lines). ${ }^{14}$

Reproduced and modified from the World Health Organization (public domain).

A

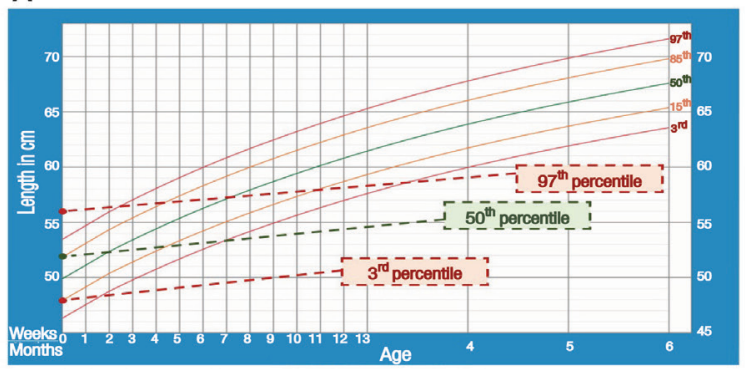

B

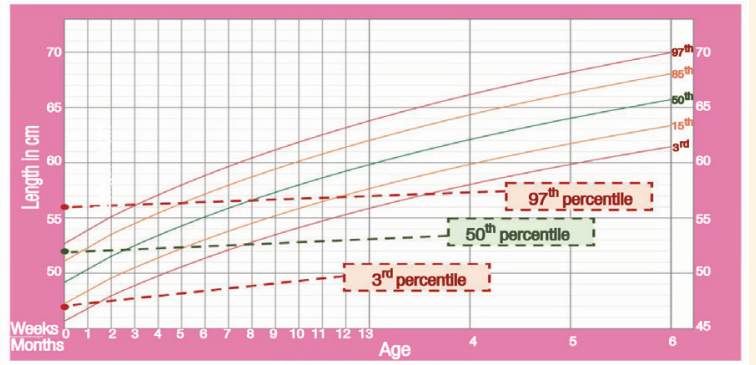

Figure 3: Comparison of length percentiles for (A) males and (B) females among Omani neonates (dotted lines) born at the Sultan Qaboos University Hospital, Muscat, Oman $(\mathrm{N}=2,766)$ with the 2006 World Health Organization standard growth charts (continuous lines). ${ }^{14}$

Reproduced and modified from the World Health Organization (public domain).

A

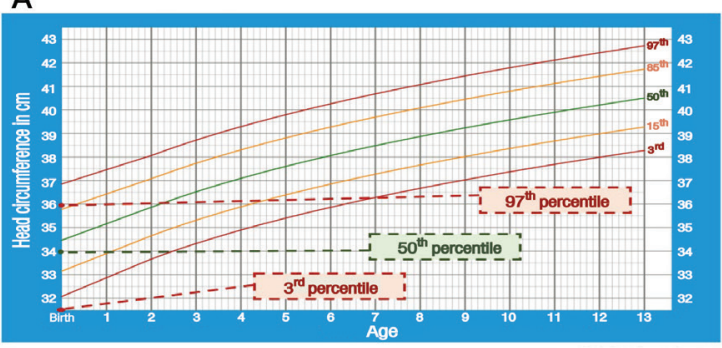

B

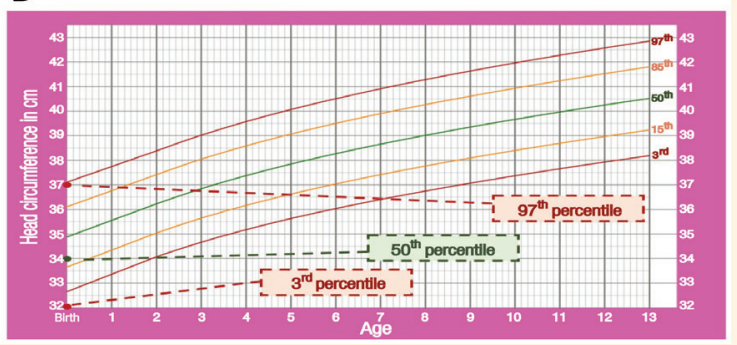

Figure 4: Comparison of head circumference percentiles for (A) males and (B) females among Omani neonates (dotted lines) born at the Sultan Qaboos University Hospital, Muscat, Oman $(\mathrm{N}=2,766)$ with the 2006 World Health Organization standard growth charts (continuous lines). ${ }^{14}$

Reproduced and modified from the World Health Organization (public domain).

and $49.1 \pm 1.89 \mathrm{~cm} ; P<0.001$ ) [Table 2]. Graphic representations of observed differences between the mean values for birth weight, length and head circumference are shown in Figures 2-4.

\section{Discussion}

The results of the current study raise concerns regarding the appropriateness of the WHO growth charts to assess the growth of Omani neonates. According to the WHO, their charts are prescriptive, indicating that any difference between chart values and those observed in a given population is due to a deviation from normal growth within that population. ${ }^{16}$ The underlying theory behind this assumption is that $90 \%$ of genetic variations are attributable to differences between people from the same continent, while only $10 \%$ are attributable to differences across continents, thus justifying the international generalisability of results from studies such as the MGRS., ${ }^{9,17}$ Nevertheless, some researchers have warned of the dangers of misinterpretations resulting from the $90 / 10 \%$ genetic variation 
rule, stating that such analyses are based on certain randomly selected common alleles, thus making general assertions about genetic variation difficult to verify. ${ }^{18}$

There is existing evidence that inhabitants of the Eastern Mediterranean region have lower anthropometric measurements compared to international growth charts, while European individuals tend to have similar or even greater anthropometric measurements. ${ }^{19-23}$ In fact, an analysis of the data from each of the six MGRS sites in isolation indicates that Oman and India had the lowest mean values for neonatal birth weight, length and head circumference in comparison to the other sites. ${ }^{9}$ As an example to showcase the variability of these measurements, mean values for birth weight, length and head circumference were $3.2 \pm 0.4 \mathrm{~kg}, 49.2 \pm 1.7 \mathrm{~cm}$ and $33.4 \pm 1.0 \mathrm{~cm}$, respectively, among Omani neonates compared to $3.6 \pm 0.5 \mathrm{~kg}, 50.4 \pm 1.9 \mathrm{~cm}$ and $34.9 \pm 1.2 \mathrm{~cm}$, respectively, among Norwegian neonates. ${ }^{9}$

According to the findings of the current study, differences in neonatal birth weight, length and head circumference were consistent across all percentile values, indicating an overestimation of growth insufficiency in the birth weight and head circumference categories and an underestimation of overgrowth in the length category. For example, $8.9 \%$ of the Omani sample in the current study would be deemed to be SGA using the WHO charts in comparison to only $3.3 \%$ when using a normal distribution curve. Furthermore, according to the WHO chart, 10.4\% of the Omani sample had microcephaly compared to $2.5 \%$ when the sample's normal distribution curve was applied. Hence, utilisation of the WHO growth charts would potentially result in 201 and 220 neonates being misclassified as SGA and microcephalic, respectively. Such discrepancies can lead to the unnecessary expenditure of health resources and undue parental anxiety. ${ }^{24}$ When babies are diagnosed as being SGA or having intrauterine growth restriction, a number of investigations are needed, including viral screening and serial ultrasound measurements. ${ }^{25}$ In addition, sophisticated investigations such as brain imaging and genetic testing are necessary for infants with microcephaly. ${ }^{6}$ According to internal financial sources at SQUH, the 421 aforementioned potential misdiagnoses would result in unnecessary interventions costing approximately USD \$250,000-300,000.

Inconsistencies were noted in the length results compared to birth weight and head circumference findings in the current study. This can perhaps be attributed to the inaccuracy of the measurement instrument, as a measuring tape was used instead of a proper length board or infantometer, as per the WHO recommendations. ${ }^{26}$ The accuracy of tape measurement is questionable, with differences between tape and length board measuring techniques reaching up to $2.23 \mathrm{~cm}^{27}$ This potential inaccuracy may have caused bias in the recorded length values, minimising the validity of the results. ${ }^{28}$ On the other hand, the findings of the present study may perhaps reflect accurate length measurements among Omani neonates. Another WHO study conducted to assess length/height disparities among the six MGRS sites found that, despite the homogeneity of the study sample, Oman accounted for the majority of the negative height variances, with more positive values obtained once this site was excluded. ${ }^{29}$ The authors stated that this negative difference was attributable to short parental stature as a result of suboptimal economic conditions which would require several generations to improve..$^{29}$ Based on this supposition, it might be assumed that neonatal height has improved due to the country's recent economic development, given that the gross domestic product has dramatically risen from USD \$42.08 billion in 2007 to USD $\$ 81.03$ billion in $2014 .^{30}$ However, this assumption might not hold because this change should also have been reflected in improved birth weight and head circumference measurements as well.

This study was based on data collected from a single centre, which potentially constitutes a major limitation. However, it is important to note that over $50 \%$ of the Omani population live in the regions of Muscat and Al-Batinah, both of which are served by SQUH. ${ }^{31}$ Therefore, it is likely that the sample was nevertheless nationally representative. In addition, like all studies based on retrospective or secondary data, information about potential confounding variables may have been missed, such as socioeconomic class and smoking. Such factors must be considered in future studies, although smoking is unlikely to have influenced the present results as its prevalence among adult Omani females is very low $(0.5 \%) .^{32}$

Future well-designed prospective studies with more rigorous methodologies are recommended in order to address the limitations of the present study and determine the need for national growth charts based on local reference data. Alternatively, researchers in Gulf Cooperation Council (GCC) countries are advised to collaborate in order to determine whether a unified GCC growth chart may be possible. As individuals from GCC countries have similar ethnicities, social norms, cultures and economies, future research may unveil potential similarities in child growth patterns within the region. Finally, proper length assessment tools are needed at SQUH in order to establish a wellstructured anthropometric training protocol to ensure 
the application of WHO recommendations. ${ }^{26}$ To this end, onsite reminder materials, regular assessments of staff competency and regular assessments of instrument accuracy and measurement reliability are also needed.

\section{Conclusion}

From the findings of the current study, it appears that the standard 2006 WHO growth charts might not accurately reflect growth patterns among Omani neonates. It is possible that such growth differences may continue into childhood, which will require further assessment of the appropriateness of childhood growth assessment tools. Meanwhile, in the absence of an Oman-specific neonatal growth assessment tool, clinicians are advised to account for potential discrepancies when using international growth assessment standards and to combine chart usage with well-informed clinical judgment.

\section{CONFLICT OF INTEREST}

The authors declare no conflicts of interest.

\section{FUNDING}

No funding was received for this study.

\section{References}

1. United Nations Children's Fund. Section 3: Measuring undernutrition in individuals. From: www.unicef.org/nutrition/ training/list.html Accessed: Oct 2017.

2. Pereira-da-Silva L. Neonatal anthropometry: A tool to evaluate the nutritional status and predict early and late risks. In: Preedy VR, Ed. Handbook of Anthropometry: Physical measures of human form in health and disease. New York, USA: Springer, 2012. Pp. 1079-104

3. Royal College of Obstetricians and Gynaecologists. Greentop guideline no. 31: The investigation and management of the smallfor-gestational-age fetus. From: www.rcog.org.uk/globalassets/ documents/guidelines/gtg_31.pdf Accessed: Oct 2017.

4. Cogill B. Anthropometric indicators measurement guide. From: www.fantaproject.org/sites/default/files/resources/anth ropometry-2003-ENG.pdf Accessed: Oct 2017.

5. Mandy GT. Large for gestational age newborn. From: www. uptodate.com/contents/large-for-gestational-age-newborn Accessed: Oct 2017

6. Woods G. Microcephaly: A clinical genetics approach. From: www.uptodate.com/contents/microcephaly-a-clinicalgenetics-approach Accessed: Oct 2017.

7. Zorlu G. New WHO child growth standards catch on. Bull World Health Organ 2011; 89:250-1. doi: 10.2471/BLT.11. 040411.

8. World Health Organization. The WHO child growth standards. From: www.who.int/childgrowth/en/ Accessed: Oct 2017.

9. WHO Multicentre Growth Reference Study Group. Enrolment and baseline characteristics in the WHO Multicentre Growth Reference Study. Acta Paediatr Suppl 2006; 450:7-15. doi: 10. 1111/j.1651-2227.2006.tb02371.x.
10. Oman Ministry of Health. New child growth standards: 2006 (World Health Organization). From: www.cdscoman.org/ uploads/cdscoman/Newsletter\%2015-3.pdf Accessed: Oct 2017.

11. Rolland-Cachera MF, Péneau S. Assessment of growth: Variations according to references and growth parameters used. Am J Clin Nutr 2011; 94:1794S-8S. doi: 10.3945/ajcn. 110.000703.

12. World Health Organization. Physical status: The use and interpretation of anthropometry - Report of a WHO Expert Committee. World Health Organ Tech Rep Ser 1995; 854:1-452.

13. Altman DG, Ohuma EO; International Fetal and Newborn Growth Consortium for the 21st Century. Statistical considerations for the development of prescriptive fetal and newborn growth standards in the INTERGROWTH-21st project. BJOG 2013; 120:71-6. doi: 10.1111/1471-0528.12031.

14. Espejo MR. WHO child growth standards: Methods and development. J R Stat Soc Ser A Stat Soc 2007; 170:512. doi: 10.1111/j.1467-985X.2007.00473_18.x.

15. Schafer JL. Multiple imputation: A primer. Stat Methods Med Res 1999; 8:3-15. doi: 10.1177/096228029900800102.

16. de Onis M, Garza C, Victora CG, Onyango AW, Frongillo EA, Martines J. The WHO Multicentre Growth Reference Study: Planning, study design, and methodology. Food Nutr Bull 2004; 25:S15-26. doi: 10.1177/15648265040251S103.

17. Jorde LB, Wooding SP. Genetic variation, classification and 'race'. Nat Genet 2004; 36:S28-33. doi: 10.1038/ng1435.

18. Risch N, Burchard E, Ziv E, Tang H. Categorization of humans in biomedical research: Genes, race and disease. Genome Biol 2002; 3:2007.1. doi: 10.1186/gb-2002-3-7-comment2007.

19. El Mouzan MI, Al Herbish AS, Al Salloum AA, Foster PJ, Al Omar AA, Qurachi MM, et al. Comparison of the 2005 growth charts for Saudi children and adolescents to the 2000 CDC growth charts. Ann Saudi Med 2008; 28:334-40. doi: 10. 5144/0256-4947.2008.334.

20. Alshimmiri MM, Al-Saleh EA, Alsaeid K, Hammoud MS, Al-Harmi JA. Birthweight percentiles by gestational age in Kuwait. Arch Gynecol Obstet 2004; 269:111-16. doi: 10.1007/ s00404-002-0434-0.

21. Payande A, Tabesh H, Shakeri MT, Saki A, Safarian M. Growth curves of preschool children in the northeast of Iran: A population-based study using quantile regression approach. Glob J Health Sci 2013; 5:9-15. doi: 10.5539/gjhs.v5n3p9.

22. Scherdel P, Botton J, Rolland-Cachera MF, Léger J, Pelé F, Ancel PY, et al. Should the WHO growth charts be used in France? PloS One 2015; 10:e0120806. doi: 10.1371/journal. pone.0120806.

23. Tinggaard J, Aksglaede L, Sørensen K, Mouritsen A, WohlfahrtVeje C, Hagen CP, et al. The 2014 Danish references from birth to 20 years for height, weight and body mass index. Acta Paediatr 2014; 103:214-24. doi: 10.1111/apa.12468.

24. So HK, Nelson EA, Sung RY, Ng PC. Implications of using World Health Organization growth reference (2007) for identifying growth problems in Hong Kong children aged 6 to 18 years. Hong Kong Med J 2011; 17:174-9.

25. Lausman A, Kingdom J; Maternal Fetal Medicine Committee. Intrauterine growth restriction: Screening, diagnosis, and management. J Obstet Gynaecol Can 2013; 35:741-8. doi: 10. 1016/S1701-2163(15)30865-3.

26. World Health Organization. Training course on child growth assessment: WHO child growth standards - Module B: Measuring a child's growth. From: www.who.int/childgrowth/ training/module_b_measuring_growth.pdf Accessed: Oct 2017.

27. Corkins MR, Lewis P, Cruse W, Gupta S, Fitzgerald J. Accuracy of infant admission lengths. Pediatrics 2002; 109:1108-11. doi: $10.1542 /$ peds.109.6.1108 
28. Ulijaszek SJ, Kerr DA. Anthropometric measurement error and the assessment of nutritional status. Br J Nutr 1999; 82:165-77. doi: 10.1017/S0007114599001348.

29. WHO Multicentre Growth Reference Study Group. Assessment of differences in linear growth among populations in the WHO Multicentre Growth Reference Study. Acta Paediatr Suppl 2006; 450:56-65. doi: 10.1111/j.1651-2227.2006.tb02376.x.

30. Trading Economics. Oman GDP: 1960-2017. From: www. tradingeconomics.com/oman/gdp Accessed: Oct 2017.
31. World Health Organization. Country cooperation strategy for WHO and Oman 2010-2015. From: http://apps.who.int/iris/ bitstream/10665/113221/1/CCS_Oman_2010_EN_14485.pdf Accessed: Oct 2017.

32. Al Riyami AA, Afifi M. Smoking in Oman: Prevalence and characteristics of smokers. East Mediterr Health J 2004; 10:600-9. 